\title{
Premium Power Quality Using Combination of Microturbine Unit and DC Distribution System
}

\begin{abstract}
Reza Noroozian $^{\dagger}$, Mehrdad Abedi* and Gevorg Gharehpetian*
Abstract - This paper discusses a DC distribution system which has been supplied by external AC systems as well as local microturbine distributed generation system in order to demonstrate an overall solution to power quality issue. Based on the dynamic model of the converter, a design procedure has been presented. In this paper, the power flow control in DC distribution system has been achieved by network converters. A suitable control strategy for these converters has been proposed, too. They have DC voltage droop regulator and novel instantaneous power regulation scheme. Also, a novel control system has been proposed for MT converter. Several case studies have been studied and the simulation results show that DC distribution system including microturbine unit can provide the premium power quality using proposed methods.
\end{abstract}

Keywords: DC Distribution System, Distributed Generation, Microturbine Droop Control, Power Electronic Converters

\section{Introduction}

Sensitive loads in modern distribution network require a high quality power supply. Also the installation of the DG close to these loads, would improve the supply quality and reliability. Unfortunately, the use of DG could result in an undesirable system voltage profile, an increase in the fault level and protection problems. In this regard, the custom power devices can improve the power quality and the reliability of sensitive loads [1]-[2]. They can convert the AC power into DC power and store the energy in capacitors and battery banks. Therefore, these devices are capable to inject $\mathrm{AC}$ power to customer during disturbances in order to enhance power quality. However, one may face the complex operation and high maintenance and initial costs [3]-[8]. If the custom power devices have been used simultaneously, the coordination of these devices for power quality and reliability enhancement would be a hard task. In order to meet the above requirements, several concepts have been proposed and studied such as "FRIENDS" [9], "Premium Power Park" [10]-[11], and "Custom power Park" [12]. The one possible design of the power quality park has been suggested in [9], which could be supplied the commercial and industrial loads in close proximity require varied quality in a power supply. Indeed, [10]-[11] describe the results of some preliminary works concerning a socalled premium power quality park. In [12], all customers of the park benefit from high quality AC power supply. In this power park, the DG unit is kept a standby to supply power when a catastrophic failure causes both the incoming feeders to trip. It must be noted that there are a number

$\dagger$ Corresponding Author: Dept. of Electrical Engineering, Faculty of Engineering, Zanjan University, Iran.(noroozian@znu.ac.ir)

* Dept. of Electrical Engineering, Amirkabir University of Technology, Iran.(abedi@aut.ac.ir and grptian@aut.ac.ir)

Received : June 23, 2009; Accepted : October 22, 2009 of technical issues in combined operation of AC and DC distribution system by DG units. For instance, as the DG would play a central role in the DC distribution system operation, the unavoidable interactions between the DG and the external AC upstream system should be carefully examined. Moreover, in previous researches [9]-[12] the impacts of the upstream or downstream fault on the premium power park have not considered. In general, a power quality park attempts to overcome some of the technical challenges caused by DGs while, providing premium power quality services. The DC distribution systems offer high power density, high efficiency and tightly regulated output voltage as needed by recent electronic loads [13]. DC distribution systems at lower voltage levels are mainly used only in specific applications, such as telecommunication equipment [14], shipboard systems [15] and traction systems [16]. The integration of DG units in AC and DC distribution systems provide additional performance which is superior to the combination of the custom power devices in the distribution system. In this paper, The DG considered is in the form of a microturbine unit. the proposed system to control power electronic converters have been used to increase the flexibility in controlling power flows to/from the external AC upstream system while DGs obtain the efficient generation and act as the backup energy source. In this paper, combined $\mathrm{AC}$ and $\mathrm{DC}$ distribution system accompanied by microturbine unit has been presented to replace the custom power park for more simpler and effective operation of commercial and industrial loads. The proposed system is able to compensate the voltage and current disturbances and can protect the sensitive load against disturbances. It is shown that the nonlinear load does not inject harmonic currents to the AC grid and unbalancing would not be occurred in the AC grid by the nonlinear load. 


\section{DC Distribution System Configuration}

Fig. 1 shows the DC distribution system including microturbine unit used for extensive investigation and case studies in this paper. Unlike a conventional UPS system, the proposed configuration has been equipped with generating sources in the form of DGs instead of batteries. The DC bus has been assumed to be lossless and has been connected to AC distribution system by two AC/DC network converters in order to enhance system reliability. These converters should have equal rated powers [1]. Considering the merits of Voltage Source Converters (VSC) [1], [17], they have been employed as interface between $\mathrm{AC}$ grid and DC bus. The power fed to the DC bus is supplied by two external AC feeders via AC/DC network converters, each connected to independent substations. In the sample system, it is assumed that a microturbine unit has been connected to the $\mathrm{DC}$ bus through its $\mathrm{AC} / \mathrm{DC}$ diode rectifier and $\mathrm{DC} / \mathrm{DC}$ converter. These DC/DC converters are called MT converter.

The loads fed by DC bus, in Fig. 1, are divided into three categories:

a) L1 is a sensitive or critical load, which requires uninterrupted sinusoidal voltage.

b) L2 is a nonlinear load, which draws harmonic current.

c) L3 is an unbalanced load, which draws unbalance current.

Power balancing in DC bus could be achieved by AC/DC network converters equipped with DC voltage regulator, which adjust the $\mathrm{DC}$ voltage at acceptable limit during steady state and dynamic conditions. Therefore the active power of microturbine unit can be injected to the DC bus and loads all connected to the DC bus could be supplied with the constant DC voltage. The power regulation of microturbine unit can be specified by various criteria such as maximum efficiency conditions or thermal load requirements [18].

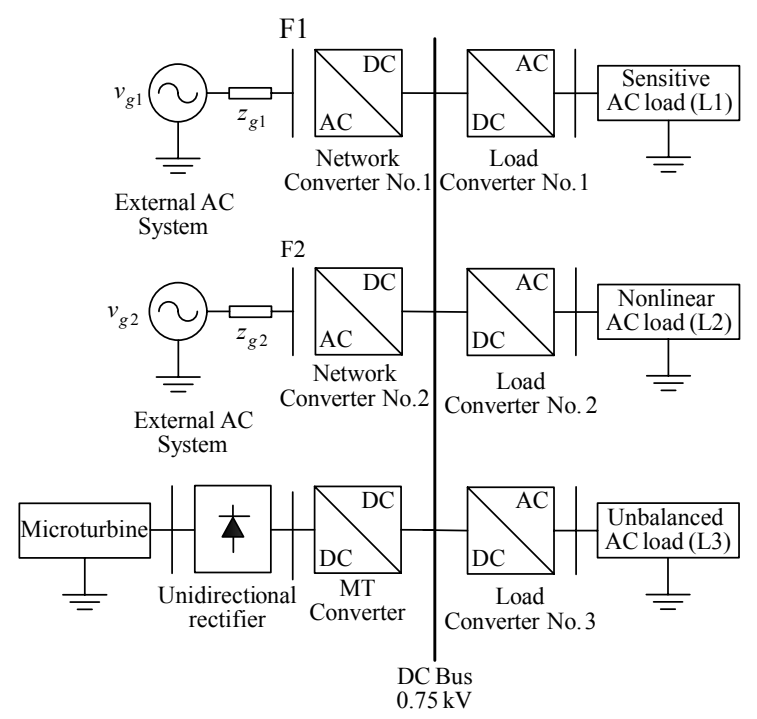

Fig. 1. DC distribution system with microturbine generation system.
It is also advisable to use all available power of microturbine unit from economical point of view. Thus, considering both technical and economical constraints, the control system of MT converter should not be designed to support the power balancing for DC bus. In the system, shown in Fig. 1, the energy storage system is not required to support the DC voltage. The main objective of the this system selection is the demonstration of the overall solution to power quality, reliability, energy-delivery efficiency problems in the lack of the energy storage system and the possibility of the DC bus utilization in parallel with external AC network or in islanding mode during AC grid outages. The proposed sample system has large potential to provide premium power quality.

\section{Power Management Strategy}

The objective of the power management strategy is to achieve optimal operational performance providing premium power quality, reliability and efficient energy dispatch. Power management strategy related to network converters should provide the reference active and reactive power signals for the power regulation. The reference active power signal of a network converter is determined by the DC voltage regulator system, which will be discussed in the next section. The reference reactive power of a network converter in AC side is specified by its reactive power management strategy which is usually Unity Power Factor (UPF) operation [19]-[20]. The reference active power of a DG unit is specified by its power management system which should consider various technical and economical constraints. In generators supplied by nonrenewable sources, e.g., microturbines and fuel cells, the active power management strategies consider various criteria, such as maximum efficiency conditions or thermal load requirements [18]. In synchronous generators connected to microturbine, power factor control, e.g. UPF, is usually adopted to maximize the active power generation [19]-[21]. The main objective that should be met for power management strategy in the sample system, are as follows:

1) The proposed control strategy is based on locally measured signals since no communication exists among microturbine unit and network converters.

2) The control scheme of network converter is based on the control loop feedback of the DC voltage because this is the only common signal for power balancing in DC bus. Moreover, each network converter is equipped with DC voltage regulator with relatively slow responses for real power control.

3) Each network converter injects the power from the external AC network to the DC bus while the available DC power generation is not sufficient for supplying system loads. It is obvious that under inverter operation each network converter injects the excessive DC power to the external AC network.

4) Simple, fast and flexible power control strategies are required to damp the proposed system oscillations, e.g., due to islanding. 
The dynamic model for the DC side of the system is shown in Fig. 2a. Two network converters, connected in parallel, can be modeled by current sources controlled by DC bus voltage signal. These converters distribute the current changes between themselves. In addition, the power reference for two bidirectional network converters is provided by DC voltage regulator. The DG unit converters and load converters are operating in the current control mode. The control philosophy for two network converters is based on feedback from the DC bus voltage, $V_{d c}$ and the reference value for the DC bus voltage. If the DC bus voltage is low, the power should be injected to the DC bus by DG units or the external AC systems. If the DC bus voltage is high, the surplus power in DC bus must be returned to external AC systems. As it can be seen in Fig 2a, we have:

$$
\begin{aligned}
& I_{n 1}(s)+I_{n 2}(s)-\left(C_{s}+C_{r}\right) s V_{d c}(s)=I_{L 1}(s)+ \\
& I_{L 2}(s)+I_{L 3}(s)-I_{M T}(s)=I_{n e t}(s) \\
& I_{n i}(s)=\frac{V_{d c, r e f n i}(s)-\frac{\omega_{l p}}{s+\omega_{l p}} V_{d c}(s)}{R_{n i}} \quad \mathrm{i}=1,2
\end{aligned}
$$

where, $I_{n 1}$ and $I_{n 2}$ are the output currents of network converters No. 1 and No. 2 respectively. $I_{M T}$ is the output currents of microturbine unit. $I_{L 1}, I_{L 2}$ and $I_{L 3}$ are the output currents of load converters No. 1, No. 2 and No. 3 respectively. $I_{n e t}$ is the current difference between the output current of all loads and DG units connected to the DC bus. $C_{S}$ is the equivalent capacitance of the network, storage and DG converters. Also $C_{r}$ is the equivalent capacitance of the load converters. $V_{d c, r e f i}$ and $I_{n i}$ are DC reference voltage and the output current of the $i$-th network converter respectively. $P_{n i}$ and $R_{n i}$ are the output DC power and the equivalent resistance of the $i$-th network converter respectively. The measured DC bus voltage is low pass filtered to attenuate the interaction between the negative sequence voltage of the $\mathrm{AC}$ side and DC bus voltage control and to enhance controller pole placement. $\omega_{l p}$ is the break-over frequency of the low pass filter (shown with LPF in Fig. 2a). Considering equations (1), (2) and (3), the measured voltage, the reference voltages in DC bus ( $V_{d c r e f 1}$ and $\left.V_{d c r e f 2}\right)$ and the current difference between the output current of all loads and DG units $\left(I_{n e t}\right)$ can be presented in one block diagram as shown in Fig. 2b. This figure shows the main structure of the DC bus voltage droop controller for the network converters. $C_{d c}$ which is equal to $C_{s}+C_{r}$, is the total equivalent capacitance of converters connected to the DC bus. From Fig. 2b, we have:

$$
\begin{aligned}
& V_{d c}(s)=\frac{\frac{1}{R_{n 1} C_{d c}}\left(s+\omega_{l p}\right)}{s^{2}+\omega_{l p} s+\frac{\left(R_{n 1}+R_{n 2}\right) \omega_{l p}}{R_{n 1} R_{n 2} C_{d c}}} V_{d c, r e f 1}(s) \\
& +\frac{\frac{1}{R_{n 2} C_{d c}}\left(s+\omega_{l p}\right)}{s^{2}+\omega_{l p} s+\frac{\left(R_{n 1}+R_{n 2}\right) \omega_{l p}}{R_{n 1} R_{n 2} C_{d c}}} V_{d c, r e f 2}(s) \\
& -\frac{\frac{1}{C_{d c}}\left(s+\omega_{l p}\right)}{s^{2}+\omega_{l p} s+\frac{\left(R_{n 1}+R_{n 2}\right) \omega_{l p}}{R_{n 1} R_{n 2} C_{d c}}} I_{n e t}(s)
\end{aligned}
$$

The closed loop transfer function is given by the following equation:

$$
p(s)=s^{2}+\omega_{l p} s+\frac{\left(R_{n 1}+R_{n 2}\right) \omega_{l p}}{R_{n 1} R_{n 2} C_{d c}}
$$

The desired characteristic equation can be expressed as:

$$
p(s)=s^{2}+2 \zeta_{n} \omega_{n} s+\omega_{n}^{2}
$$

where, $\zeta_{n}$ and $\omega_{n}$ are the desired closed loop damping and bandwidth, respectively. The value of DC bus equivalent capacitors determines the performance of the DC voltage control system.

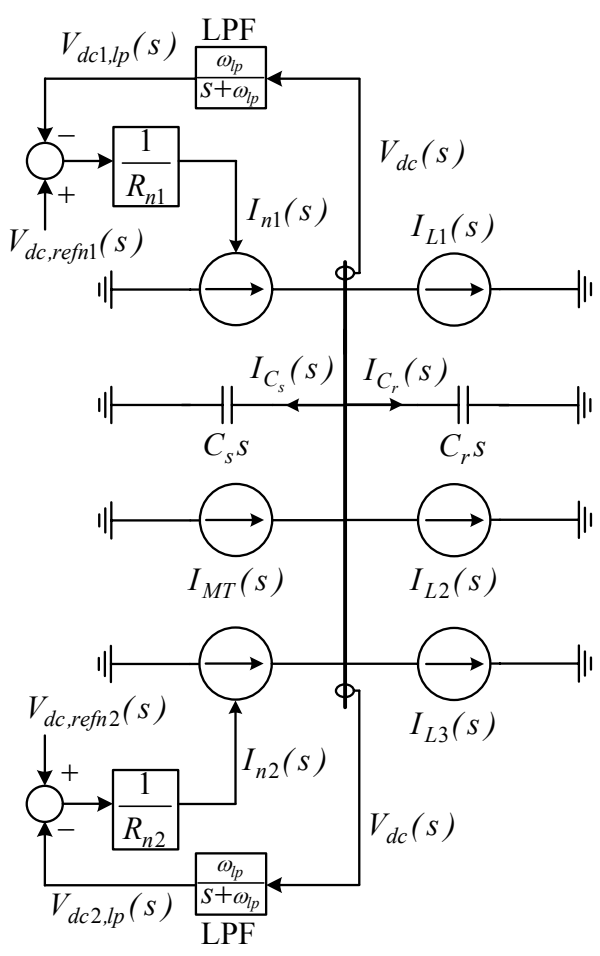

Fig. 2a. DC side dynamic model. 


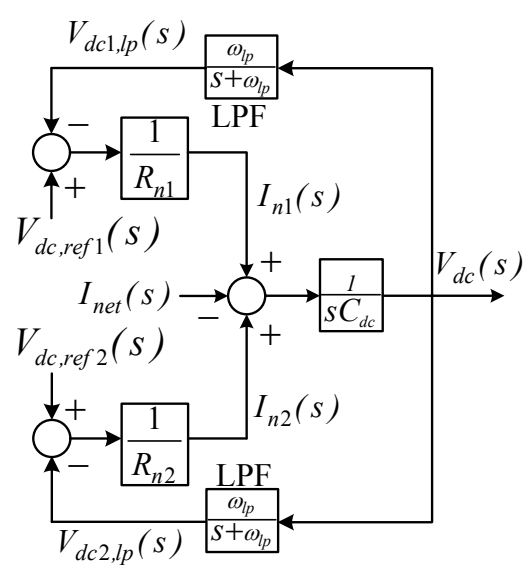

Fig. 2b. Structure of the DC bus voltage droop controller.

The total required DC bus capacitor, $C_{d c}$, can be determined by using equations (4) and (5):

$$
\begin{gathered}
C_{d c}=C_{s}+C_{r}=\frac{\left(R_{n 1}+R_{n 2}\right) 4 \zeta_{n}^{2}}{R_{n 1} R_{n 2} \omega_{l p}} \\
\omega_{n}=\frac{1}{2 \zeta_{n} \omega_{l p}}
\end{gathered}
$$

The steady state model for the DC side of the system is shown in Fig. 3a. The above mentioned equations can be written for the steady state condition as follows:

$$
\begin{gathered}
I_{n 1}+I_{n 2}=I_{n e t} \\
I_{n \mathrm{i}}(s)=\frac{V_{d c, r e f \mathrm{i}}-V_{d c}}{R_{n \mathrm{i}}} \quad \mathrm{i}=1,2
\end{gathered}
$$

For $P_{n i}$, we have:

$$
P_{n i}=V_{d c} I_{n \mathrm{i}}=\frac{V_{d c}\left(V_{d c, r e f \mathrm{i}}-V_{d c}\right)}{R_{n \mathrm{i}}} \quad \mathrm{i}=1,2
$$

Substituting equation (9) in the equation (8) we get:

$$
V_{d c}=\frac{R_{n 2} V_{d c, r e f 1}+R_{n 1} V_{d c, r e f 2}-R_{n 1} R_{n 2} I_{n e t}}{R_{n 1}+R_{n 2}}
$$

Using equations (9) and (11), we obtain:

$$
\begin{aligned}
& I_{n 1}=\frac{R_{n 2} I_{n e t}}{R_{n 1}+R_{n 2}}+\frac{V_{d c, r e f 1}-V_{d c, r e f 2}}{R_{n 1}+R_{n 2}} \\
& I_{n 2}=\frac{R_{n 1} I_{n e t}}{R_{n 1}+R_{n 2}}-\frac{V_{d c, r e f 1}-V_{d c, r e f 2}}{R_{n 1}+R_{n 2}}
\end{aligned}
$$

and,

$$
I_{c}=\frac{V_{d c, r e f 1}-V_{d c, r e f 2}}{R_{n 1}+R_{n 2}}
$$

It is clear that if $V_{d c, r e f 1}=V_{d c, r e f 2}=V_{d c, r e f}$, then the circulating current, $I_{c}$, is equal to zero. In addition, if $R_{n 1}=R_{n 2}=R_{n}$, then the injected currents to the DC bus via network converters, $I_{n 1}$ and $I_{n 2}$, are equal. However, the proper load sharing can be obtained by the appropriate selection of $R_{n \mathrm{i}}$. The voltage droop, $\delta$, can be defined as follows:

$$
\delta=\frac{V_{d c, r e f 1}-V_{d c}}{V_{d c, r e f 1}}=\frac{V_{d c, r e f 2}-V_{d c}}{V_{d c, r e f 2}}=\frac{V_{d c, r e f}-V_{d c}}{V_{d c, r e f}}
$$

The equation (10) can be rewritten in the following form:

$$
P_{n \mathrm{i}}=\frac{\delta(1-\delta) V_{d c, r e f \mathrm{i}}^{2}}{R_{n \mathrm{i}}} \quad \mathrm{i}=1,2
$$

At rated power conditions, equation (16) can be rewritten as follows:

$$
\begin{array}{cc}
P_{n \mathrm{i}, \text { rated }}=\frac{\delta_{n}\left(1-\delta_{n}\right) V_{d c, \text { ref } \mathrm{i}}^{2}}{R_{n \mathrm{i}}} & \mathrm{i}=1,2 \\
R_{n \mathrm{i}}=\frac{\delta_{n}\left(1-\delta_{n}\right) V_{d c, \text { ref } \mathrm{i}}^{2}}{P_{\text {ni,rated }}} & \mathrm{i}=1,2
\end{array}
$$

Using equations (6) and (18), we have:

$$
C_{d c}=\frac{2 \zeta_{n}^{2}\left(P_{n 1, \text { rated }} V_{d c, \text { ref } 1}^{2}+P_{n 2, \text { rated }} V_{d c, \text { ref } 2}^{2}\right)}{\omega_{l p} \delta_{n}\left(1-\delta_{n}\right) V_{d c, \text { ref } 1}^{2} V_{d c, \text { ref } 2}^{2}}
$$

It is clear that if $V_{d c, r e f 1}=V_{d c, r e f 2}=V_{d c, r e f}$ and $P_{n 1, \text { rated }}=P_{n 2, \text { rated }}=P_{n, \text { rated }}$, then the total required DC bus capacitor can be determined by the following equation:

$$
C_{d c}=\frac{4 \zeta_{n}^{2} P_{n, \text { rated }}}{\omega_{l p} \delta_{n}\left(1-\delta_{n}\right) V_{d c, r e f}^{2}}
$$

Fig. 3b shows the steady state droop characteristics of network converters. The output current of these converters can be controlled by the slope of the voltage droop characteristics. For suitable operation of network converters, DC bus voltage can be changed within two threshold values, $V_{\text {refu }}$ and $V_{\text {refl }}$. By the proposed control strategy for network converters, the DC bus voltage must be kept stable within an acceptable limit. Moreover, if the DC bus voltage exceeds the threshold value $V_{\text {refMT }}$, the power produced by DG units is cancelled out. 


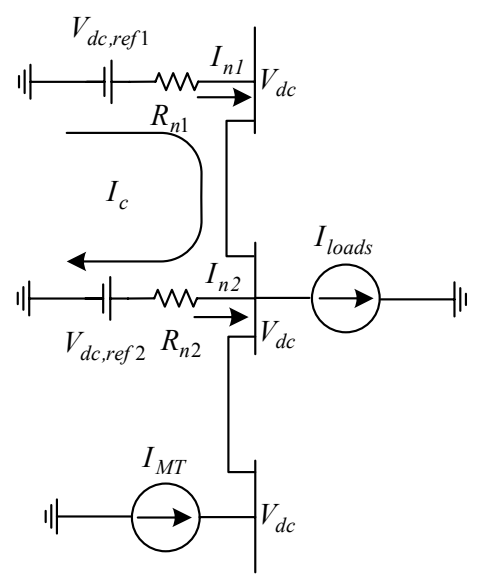

Fig. 3a. DC side steady state model.

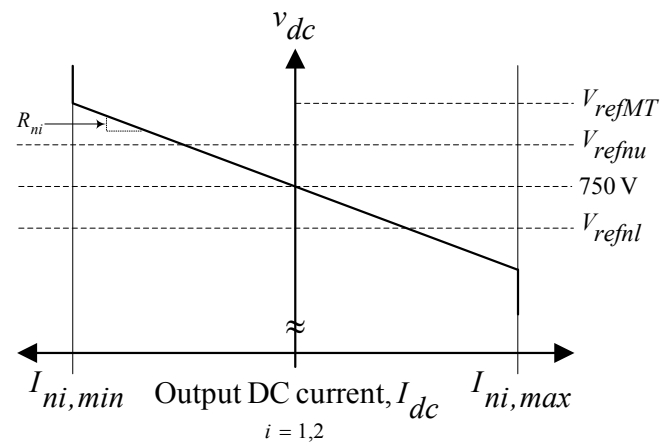

Fig. 3b. Droop characteristics of network converters.

In the system, the power difference between the load demands and power generation of DG units is calculated as follows:

$$
P_{n 1}+P_{n 2}+P_{M T}=P_{\text {loads }}
$$

$P_{M T}$ is the output power of a microturbine unit. $P_{\text {loads }}$ is total power consumed by all loads connected to the DC bus. It is obvious that the injected power by network converters to the DC bus, $P_{n 1}$ and $P_{n 2}$, can be classified into two main categories respect to power flow direction, namely:

1) Forward-flow mode of operation: in which the $A C$ power is injected to the network converter by the $\mathrm{AC}$ grid, in order to supply the DC bus.

2) Reverse-flow mode of operation: when the additional power available in the DC bus could be injected to the AC grid via network converter.

\section{Control Strategies of Converters}

The main objective of the control strategy for each converter, connected to the DC bus, is the enhancement of the power quality, reliability and energy efficiency. In this paper, suitable control strategies for each converter have been presented. These strategies are mainly based on the control of the DC bus voltage within acceptable limit.

\subsection{Circuit Configuration and Control Scheme for Network Converters}

The equivalent circuit of a network converter is shown in Fig. 4. This converter is represented with three ideal current sources $i_{f a}^{r e f}, i_{f b}^{r e f}$ and $i_{f c}^{r e f}$. The converter manages the amount of the current injected to the DC bus and vice versa. As it can be seen in Fig. 4, the input signals of the network converter controller are source phase voltages, $v_{a}, v_{b}$ and $v_{c}$, source line currents, $i_{a}, i_{b}$ and $i_{c}$, three phase output currents for this converter $i_{f a}, i_{f b}$ and $i_{f c}$, DC bus voltage $v_{d c}$ and the reference DC voltage, $V_{\text {dcref }} . L_{f}$ is the inductance of the converter filter. $R_{g}$ and $L_{g}$ are the resistance and inductance of the $\mathrm{AC}$ grid. This controller uses the Hysteresis Current Control (HCC) switching technique. As it can be seen in Fig. 4, we have:

$$
\left[\begin{array}{l}
i_{a} \\
i_{b} \\
i_{c}
\end{array}\right]=-\left[\begin{array}{l}
i_{f a} \\
i_{f b} \\
i_{f c}
\end{array}\right]
$$

The circuit configuration and control scheme for each network converter has been depicted in Fig. 5a. The main part of this scheme is DC voltage regulator. In this paper, the droop control strategy has been used for each network converter, since it does not require any communication system [22]. More details of the DC voltage regulator are shown in Fig. 5b. It is obvious when the DC bus voltage, $v_{d c}$, remains constant at the level of $V_{d c, \text { ref }}$, the power balancing occurs in the DC bus. As shown in Fig. 5b, the DC voltage of each network converter (i.e., voltage at DC bus) is measured and after passing through a low pass filter, $v_{d c, l p}$ could be compared with the reference voltage (i.e.,

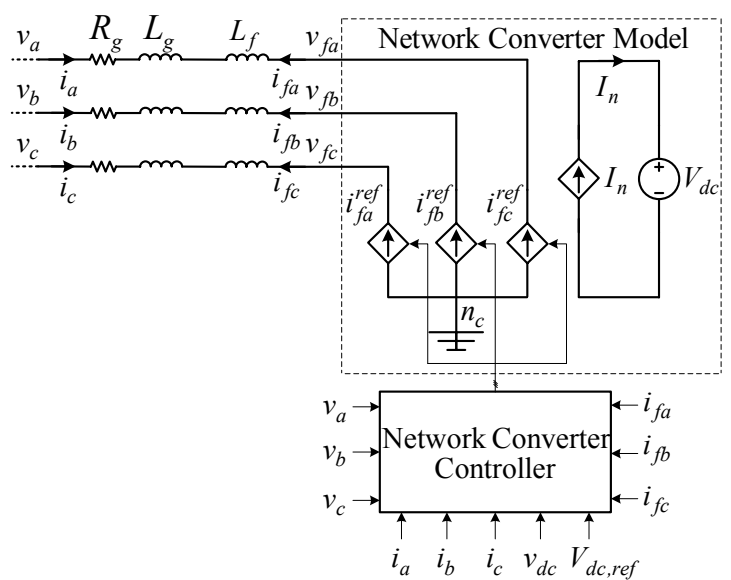

Fig. 4. Equivalent circuit of network converter. 


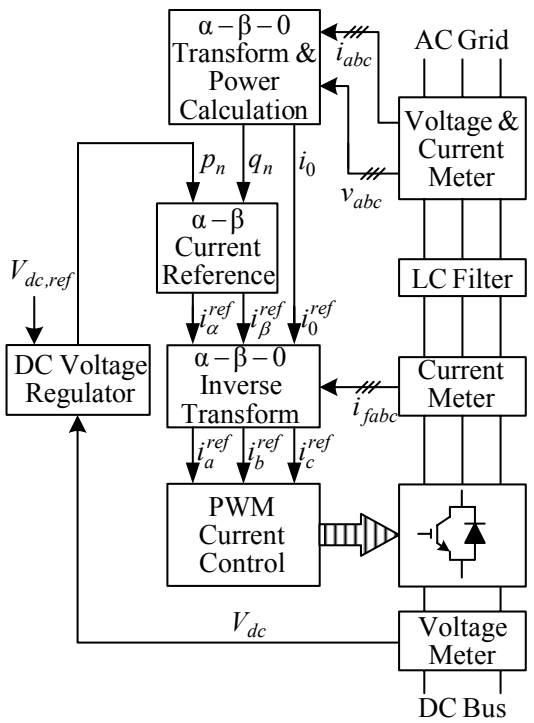

Fig. 5a. Block diagram of network converter controller.

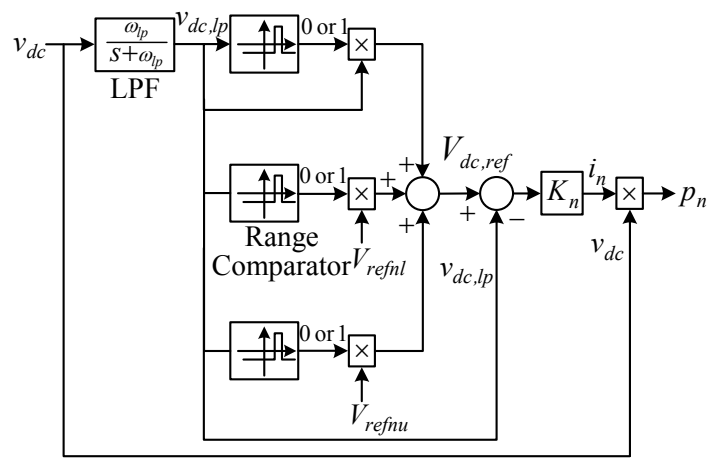

Fig. 5b. DC voltage regulator.

$\left.V_{d c, r e f}\right)$. Then the DC voltage error can be fed to the droop controller whose droop is $K_{n}$, in order to obtain the injected current (i.e., $i_{n}$ ) to the DC bus. The multiplication of $v_{d c}$ and $i_{n}$ determines the injected power to the DC bus of each network converter (i.e., $p_{n}$ ). For the regulator shown in Fig. 5b, we have:

$$
\begin{gathered}
i_{n}=K_{n}\left(V_{d c, r e f}-v_{d c, l p}\right) \\
p_{n}=v_{d c} i_{n, r e f}
\end{gathered}
$$

Using equations (23) and (24), we obtain:

$$
p_{n}=K_{n} v_{d c}\left(V_{d c, r e f}-v_{d c, l p}\right)
$$

The above mentioned equations in steady state condition can be rewritten as follows:

$$
\begin{gathered}
I_{n}=K_{n}\left(V_{d c, r e f}-V_{d c}\right) \\
P_{n}=I_{n} V_{d c}
\end{gathered}
$$

$$
P_{n}=K_{n} V_{d c}\left(V_{d c, r e f}-V_{d c}\right)
$$

Considering the equations (10) and (28), the steady state droop is:

$$
R_{n}=\frac{1}{K_{n}}
$$

The $\alpha-\beta-0$ transformation and the power calculation box in Fig. 5a perform the following equations:

$$
\begin{gathered}
{\left[\begin{array}{l}
v_{\alpha} \\
v_{\beta} \\
v_{0}
\end{array}\right]=T_{\alpha \beta 0}\left[\begin{array}{l}
v_{a} \\
v_{b} \\
v_{c}
\end{array}\right],\left[\begin{array}{l}
i_{\alpha} \\
i_{\beta} \\
i_{0}
\end{array}\right]=T_{\alpha \beta 0}\left[\begin{array}{l}
i_{a} \\
i_{b} \\
i_{c}
\end{array}\right]} \\
T_{\alpha \beta 0}=\sqrt{\frac{2}{3}}\left[\begin{array}{ccc}
\frac{1}{\sqrt{2}} & \frac{1}{\sqrt{2}} & \frac{1}{\sqrt{2}} \\
1 & -\frac{1}{2} & -\frac{1}{2} \\
0 & \frac{\sqrt{3}}{2} & -\frac{\sqrt{3}}{2}
\end{array}\right] \\
q_{n}=-v_{\beta} \cdot i_{\alpha}+v_{\alpha} \cdot i_{\beta}
\end{gathered}
$$

The reference active power, $p_{n}$, can be produced by the DC voltage regulator (equation (24)). In addition the reference reactive power, $q_{n}$, can be produced by the power calculation box (equation (30)). In the present work, stationary transformation (Clarke transformation) has been used in order to provide simple and fast control strategy. Thus, the $\alpha-\beta$ component related to the reference current of each network converter can be expressed by the equation (32).

$$
\left[\begin{array}{l}
i_{\alpha}^{r e f} \\
i_{\beta}^{r e f}
\end{array}\right]=\frac{1}{v_{\alpha}^{2}+v_{\beta}^{2}}\left[\begin{array}{cc}
v_{\alpha} & -v_{\beta} \\
v_{\beta} & v_{\alpha}
\end{array}\right]\left[\begin{array}{l}
p_{n} \\
q_{n}
\end{array}\right]
$$

The zero-sequence current in the zero coordinate frame of reference is $i_{0}$, and it is clear that:

$$
i_{0}^{r e f}=i_{0}
$$

Finally, the $\alpha-\beta-0$ inverse transformation box shown in Fig. 5a calculates the three-phase current references to be fed into the Hysteresis Current Control (HCC) scheme. Thus:

$$
\left[\begin{array}{l}
i_{a}^{r e f} \\
i_{b}^{r e f} \\
i_{c}^{r e f}
\end{array}\right]=T_{a b c}\left[\begin{array}{l}
i_{0}^{r e f} \\
i_{\alpha}^{r e f} \\
i_{\beta}^{r e f}
\end{array}\right]
$$




$$
\begin{aligned}
& T_{a b c}=\sqrt{\frac{2}{3}}\left[\begin{array}{ccc}
\frac{1}{\sqrt{2}} & 1 & 0 \\
\frac{1}{\sqrt{2}} & -\frac{1}{2} & \frac{\sqrt{3}}{2} \\
\frac{1}{\sqrt{2}} & -\frac{1}{2} & -\frac{\sqrt{3}}{2}
\end{array}\right] \\
& {\left[\begin{array}{l}
i_{f a}^{r e f} \\
i_{f b}^{r e f} \\
i_{f c}^{r e f}
\end{array}\right]=-\left[\begin{array}{l}
i_{a}^{r e f} \\
i_{b}^{r e f} \\
i_{c}^{r e f}
\end{array}\right]}
\end{aligned}
$$

The comparison of the calculated reference currents and the actual currents generated by the network converter will result in the error signal, which controls the switches of the converter.

\subsection{Circuit Configuration and Control Scheme for Microturbine Unit}

Fig. 6 shows the block diagram of microturbine (MT) generation unit. MT generation unit has a common rotating shaft, associated with the Permanent Magnet Synchronous Generator (PMSG), combustor, compressor, and turbine. PMSG is connected to the DC bus via three phase unidirectional rectifier as well as DC/DC converter [23]. In this plant the turbine is high speed type $(50,000-90,000 \mathrm{rpm})$ including airfoil bearing. PMSG provides a high frequency AC power in the range of $1-2 \mathrm{kHz}$. The output of PSMG is rectified by three phase unidirectional diode rectifier. In order to implement the control strategy on injected DC power to the DC bus, a DC/DC converter is required.

The equivalent circuit of the MT converter is shown in Fig. 7. This converter is represented with an ideal current source, $i_{f M T}^{r e f}$. The converter manages the amount of the current injected to the DC bus. The input signals of MT converter controller are MT units output voltage $v_{M T}$, MT unit output current $i_{M T}$, reference active power of a MT unit, $P_{M T, \text { ref }} \pm p_{m}$.

The control strategy for a MT converter has been shown in Fig. 8. In this control scheme, the reference active power, $P_{M T, r e f}$ is specified by the related active power management

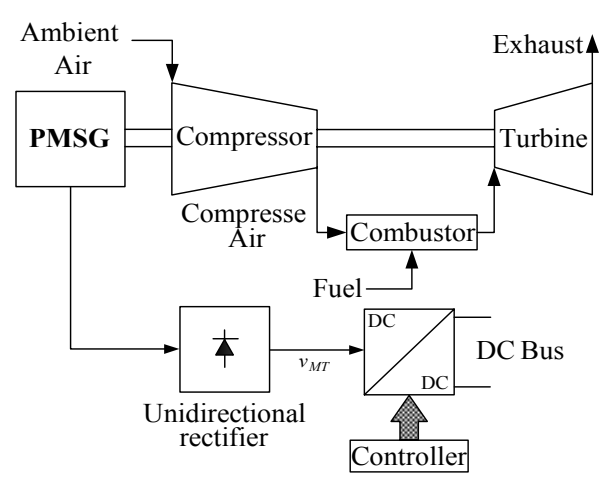

Fig. 6. Block diagram of microturbine system.

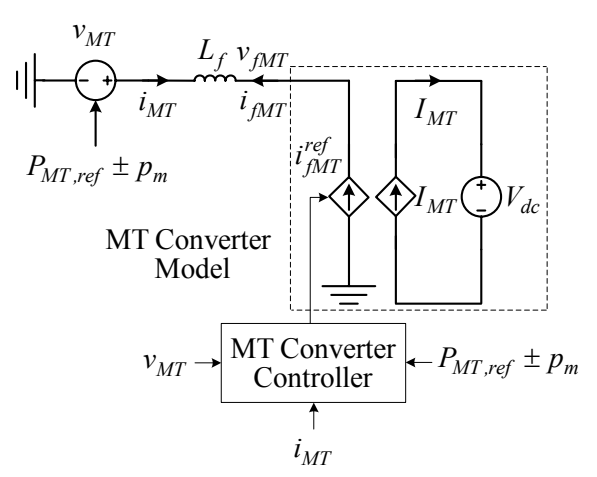

Fig. 7. Equivalent circuit of MT converter.

strategy. The active power variation, $p_{m}$ is specified by the MT voltage droop controller. The DC voltage error can be fed to the proportional-integral (PI) controller whose gain is $K_{m}$, in order to obtain the injected current (i.e., $\left.i_{m}\right)$ to the DC bus. The multiplication of $v_{d c}$ and $i_{m}$ determines the injected power to the DC bus of MT converter (i.e., $p_{m}$ ). If the voltage exceeds the higher reference value, $V_{r e f n u}$, the signal $p_{m}$ is negative and the MT converter reduces the injected power to DC bus and if it is lower than the lower reference value, $V_{\text {refnl }}$, the signal $p_{m}$ is positive and the MT converter increases the injected power to DC bus. The reference current, $i_{f M T}^{r e f}$, can be determined as follows:

$$
i_{f M T}^{r e f}=\frac{P_{M T, r e f} \pm p_{m}}{v_{M T}}
$$

The comparison of the calculated reference current $i_{f M T}^{r e f}$, and the actual currents generated by the MT converter $i_{f M T}$ will result in the error signal, which is fed to the HCC system which determines the switching pattern of MT converters. If the DC bus voltage exceeds the threshold value $V_{\text {refMT }}$, the power produced by MT unit is cancelled out.

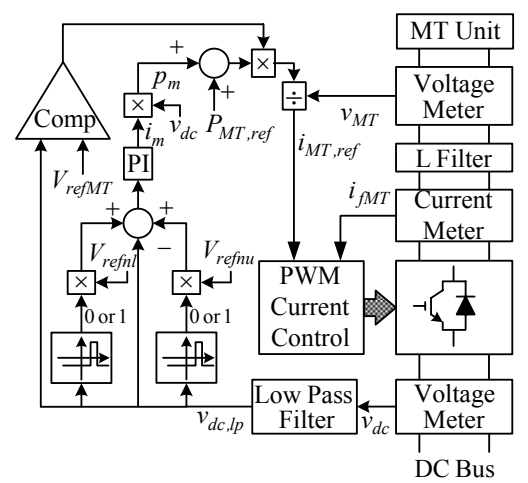

Fig. 8. Block diagram of microturbine controller. 


\subsection{Circuit Configuration and Control Scheme for Load Converters}

The load converter is voltage source converter (VSC) with neutral clamped DC capacitors. This topology is characterized by the connection of the neutral point of the load to the midpoint of the clamped DC capacitors. The equivalent circuit of the load converter is shown in Fig. 9. This converter is represented with three voltage sources, $v_{f a}^{r e f}$, $v_{f b}^{r e f}$ and $v_{f c}^{r e f}$. The equations describing load converter voltages and currents are expressed by the following equation:

$$
\left[\begin{array}{l}
v_{f a} \\
v_{f b} \\
v_{f c}
\end{array}\right]=\left[\begin{array}{c}
v_{l a} \\
v_{l b} \\
v_{l c}
\end{array}\right]+\left[\begin{array}{ccc}
L_{f} & 0 & 0 \\
0 & L_{f} & 0 \\
0 & 0 & L_{f}
\end{array}\right] \frac{\mathrm{d}}{\mathrm{dt}}\left[\begin{array}{c}
i_{f a} \\
i_{f b} \\
i_{f c}
\end{array}\right]
$$

where, $v_{f a}, v_{f b}$ and $v_{f c}$ are line to neutral three phase output voltages of the load converter. $i_{f a}, i_{f b}$ and $i_{f c}$ are three phase output currents. $v_{l a}, v_{l b}$ and $v_{l c}$ are line to neutral three phase voltages of $\mathrm{AC}$ loads.

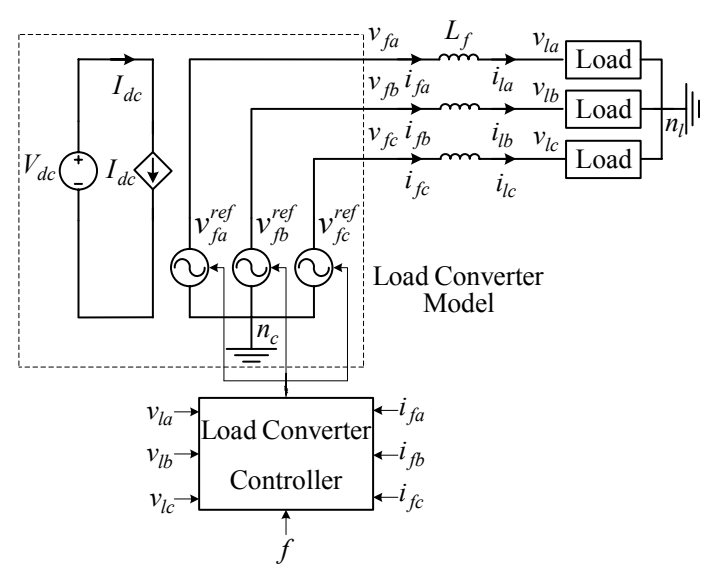

Fig. 9. Equivalent circuit of a load converter.

The voltage equations in the $d-q-0$ reference frame are as follows:

$$
\begin{aligned}
& {\left[\begin{array}{c}
v_{f d} \\
v_{f q} \\
v_{f 0}
\end{array}\right]=\left[\begin{array}{c}
v_{l d} \\
v_{l q} \\
v_{l 0}
\end{array}\right]+\left[\begin{array}{ccc}
L_{f} & 0 & 0 \\
0 & L_{f} & 0 \\
0 & 0 & L_{f}
\end{array}\right] \frac{\mathrm{d}}{\mathrm{dt}}\left[\begin{array}{c}
i_{f d} \\
i_{f q} \\
i_{f 0}
\end{array}\right]} \\
& +\left[\begin{array}{ccc}
0 & -\omega L_{f} & 0 \\
\omega L_{f} & 0 & 0 \\
0 & 0 & 0
\end{array}\right]\left[\begin{array}{c}
i_{f d} \\
i_{f q} \\
i_{f 0}
\end{array}\right]
\end{aligned}
$$

The circuit configuration and control scheme for each converter has been depicted in Fig. 10. The load converter between the DC bus and AC loads can be controlled by
$V-f$ control strategy, which regulates the voltage and the frequency of AC loads. In the $V-f$ controller, it is clear that:

1) Frequency $(\omega)$ can be obtained by Phase Lock Loop (PLL) using desirable frequency (e.g., $50 \mathrm{~Hz}$ ).

2) The load phase voltages $\left(v_{l a}, v_{l b}\right.$ and $\left.v_{l c}\right)$ can be detected and transformed to the stationary reference frame with Clarke transformations and then into a $d-q-0$ synchronously rotating reference frame using following equations:

$$
\begin{gathered}
{\left[\begin{array}{l}
v_{l \alpha} \\
v_{l \beta} \\
v_{l 0}
\end{array}\right]=T_{\alpha \beta 0}\left[\begin{array}{l}
v_{l a} \\
v_{l b} \\
v_{l c}
\end{array}\right]} \\
{\left[\begin{array}{l}
v_{l d} \\
v_{l q} \\
v_{l 0}
\end{array}\right]=T_{d q 0}\left[\begin{array}{c}
v_{l \alpha} \\
v_{l \beta} \\
v_{l 0}
\end{array}\right]} \\
T_{d q 0}=T_{d q 0}^{-1}=\left[\begin{array}{ccc}
\cos (\omega t) & \sin (\omega t) & 0 \\
\sin (\omega t) & -\cos (\omega t) & 0 \\
0 & 0 & 1
\end{array}\right]
\end{gathered}
$$

The load phase voltage should be kept balanced and sinusoidal with constant amplitude and frequency. Therefore the expected load voltage in the $d-q-0$ reference frame should have only the following value:

$$
\left[\begin{array}{c}
v_{l d}^{\exp } \\
v_{l p}^{\exp } \\
v_{l 0}^{\exp }
\end{array}\right]=\left[\begin{array}{c}
0 \\
0.4 \sqrt{\frac{2}{3}} \\
0
\end{array}\right]
$$

The reference load current loops in the $d-q-0$ coordinate are:

$$
\left[\begin{array}{l}
i_{l d}^{r e f} \\
i_{l q}^{r e f} \\
i_{l 0}^{r e f}
\end{array}\right]=\left[\begin{array}{l}
\operatorname{PI}\left(v_{l d}-v_{l d}^{e x p}\right) \\
\operatorname{PI}\left(v_{l q}-v_{l q}^{e x p}\right) \\
\operatorname{PI}\left(v_{l 0}-v_{l 0}^{e x p}\right)
\end{array}\right]
$$

The output signals from PI controller can be expressed by the equation (43).

$$
\left[\begin{array}{c}
v_{f d}^{r e f} \\
v_{f q}^{r e f} \\
v_{f 0}^{r e f}
\end{array}\right]=\left[\begin{array}{c}
v_{l d} \\
v_{l q} \\
v_{l 0}
\end{array}\right]+\left[\begin{array}{c}
\mathrm{PI}\left(i_{l d}^{r e f}-i_{f d}\right) \\
\mathrm{PI}\left(i_{l q}^{r e f}-i_{f q}\right) \\
\mathrm{PI}\left(i_{l 0}^{r e f}-i_{f 0}\right)
\end{array}\right]+\left[\begin{array}{c}
-\omega L_{f} i_{f d} \\
\omega L_{f} i_{f q} \\
0
\end{array}\right]
$$

The reference output voltages for the load converter are transformed to the $a-b-c$ by using inverse synchronously rotating and stationary reference frames. 


$$
\begin{gathered}
{\left[\begin{array}{c}
v_{f \alpha}^{r e f} \\
v_{f \beta}^{r e f} \\
v_{f 0}^{r e f}
\end{array}\right]=T_{d q 0}^{-1}\left[\begin{array}{c}
v_{f d}^{r e f} \\
v_{f q}^{r e f} \\
v_{f 0}^{r e f}
\end{array}\right]} \\
{\left[\begin{array}{c}
v_{f a}^{r e f} \\
v_{f b}^{r e f} \\
v_{f c}^{r e f}
\end{array}\right]=T_{a b c}\left[\begin{array}{c}
v_{f \alpha}^{r e f} \\
v_{f \beta}^{r e f} \\
v_{f 0}^{r e f}
\end{array}\right]}
\end{gathered}
$$

Then the available voltages in the $a-b-c$ coordinate are compared with the triangular wave provided by PWM voltage control block. Therefore the output provides suitable switching pattern of each load converter.

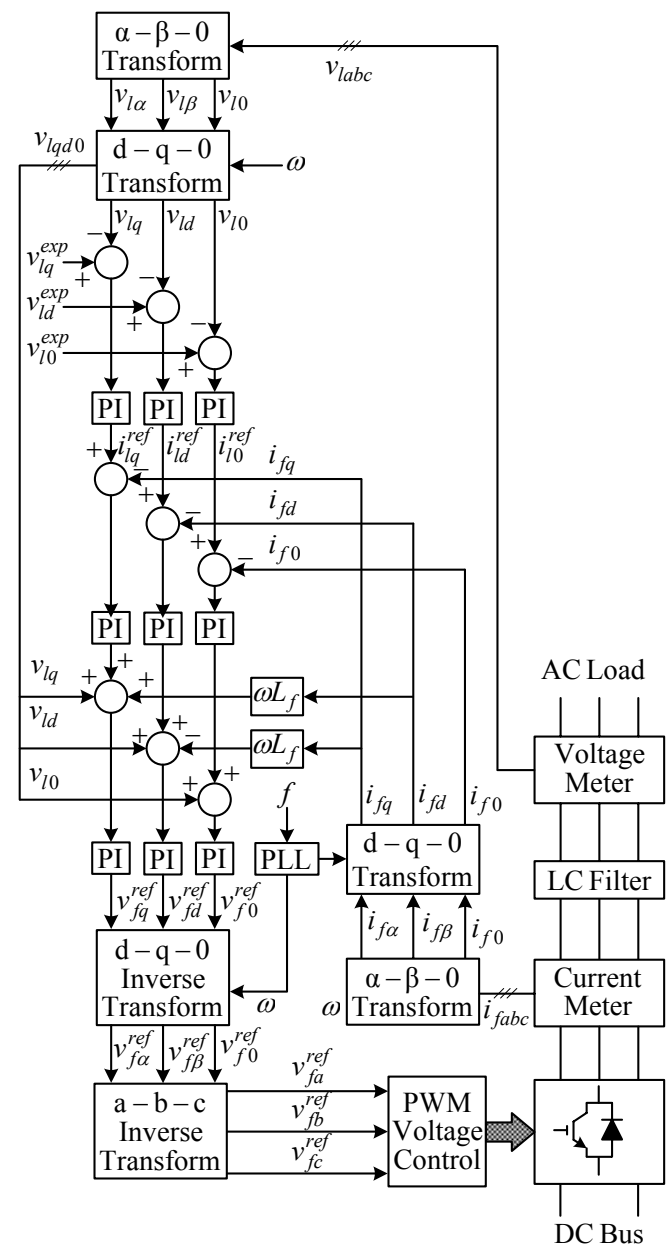

Fig. 10. Control scheme for load converter.

\section{Simulation Results}

The system shown in Fig. 1 has been simulated by PSCAD/EMTDC software in order to study the combined $\mathrm{AC}$ and $\mathrm{DC}$ distribution system from power quality problems point of view. It is assumed that $100 \mathrm{~kW}$ network converters are in service. It is also assumed that the refer- ence DC voltage is $V_{d c, r e f}=750 \mathrm{~V}$ and the nominal droop is 5 percent, $V_{\text {refnl }}=712.5 \mathrm{~V}$ and $V_{\text {refnu }}=787.5 \mathrm{~V}$. The rated power for a microturbine unit is assumed to be $20 \mathrm{~kW}$.

\subsection{Voltage Interruption in AC Distribution System}

In this section a three phase fault at point F2 of Fig. 1 has been simulated. The result is a voltage interruption during the time period of $\mathrm{t}=10.3 \mathrm{~s}$ till $\mathrm{t}=10$. 5s. Fig. 11a illustrates the phase voltages $\left(V_{a 2}, V_{b 2}\right.$ and $\left.V_{c 2}\right)$ at point F2. Fig. 11b depicts the variations of the active power in external AC grids ( $P_{n 1}$ and $P_{n 2}$ ), as well as power associated with $\mathrm{AC}$ and DC loads connected to the DC bus (i.e., $\left.P_{L \mathrm{~s}}=P_{L 1}+P_{L 2}+P_{L 3}\right)$, and the output power of MT unit injected to the DC bus (i.e., $P_{M T}$ ).

Fig. 11c shows the DC bus voltage which remains constant during voltage interruption using the proposed power regulation scheme for network converters. As it can be seen the actual DC bus voltage $\left(V_{d c}\right)$ follows the DC voltage $\left(V_{d c, d y}\right)$ and matches the results determined by equation (3).

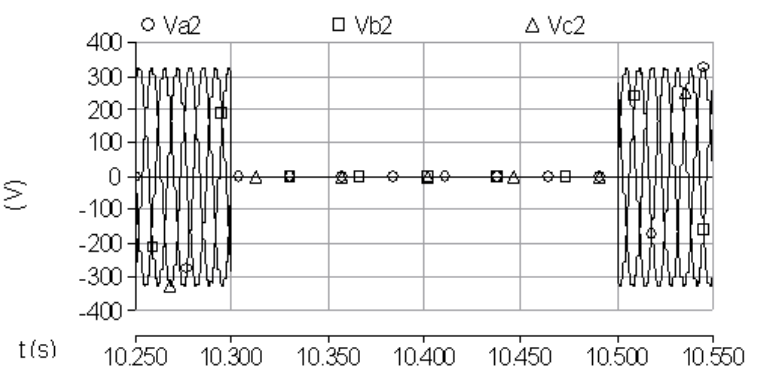

Fig. 11a. Phase voltages in AC side of network converter No. 2.

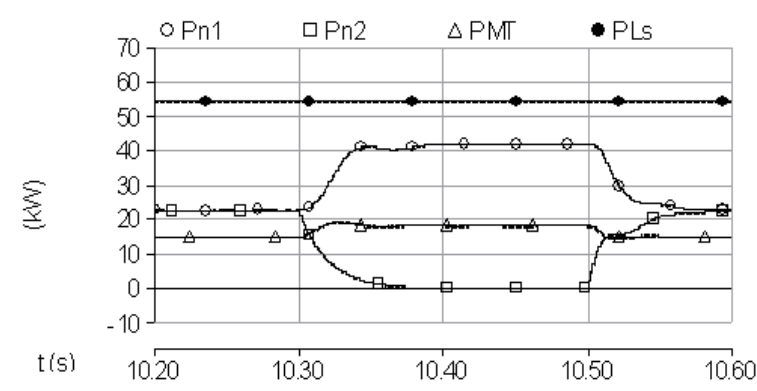

Fig. 11b. (a) Active power variations.

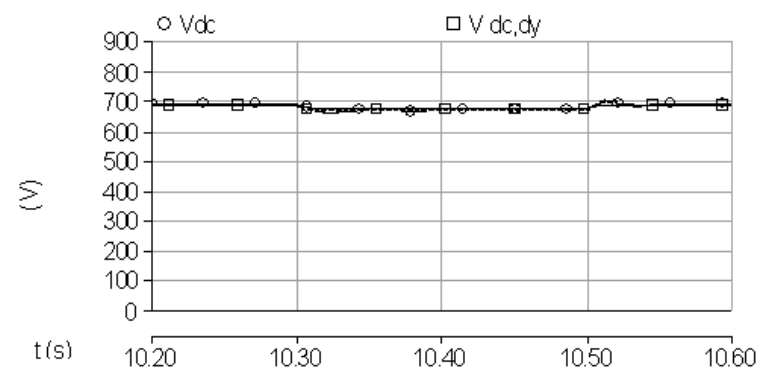

Fig. 11c. DC bus voltage. 
Fig. 12 illustrate the phase voltages at the terminal of the sensitive load ( $V_{a L 1}, V_{b L 1}$ and $\left.V_{c L 1}\right)$, the nonlinear load $\left(V_{a L 2}, V_{b L 2}\right.$ and $\left.V_{c L 2}\right)$ and the unbalanced load $\left(V_{a L 2}\right.$, $V_{b L 2}$ and $\left.V_{c L 2}\right)$, respectively. It can be seen that the high quality voltages have been provided for AC loads. To quantify the level of the voltage unbalance, the percentage of unbalance is expressed in accordance with the definition of the "degree of unbalance in three phase system" [24]. In this case, the negative sequence unbalance is lower then $1 \%$ which is acceptable. It must be noticed that international standards admit unbalances lower than $2 \%$ [24].

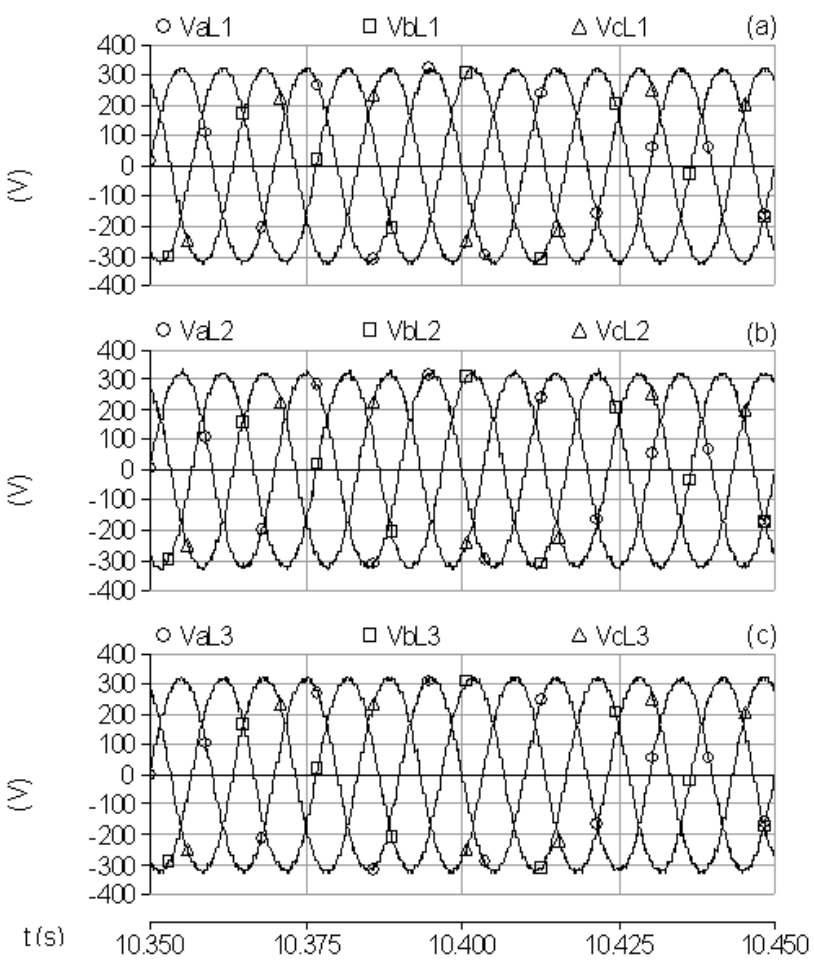

Fig. 12. Grid-side phase voltages of the load converters No. 1 (L1), No. 2 (L2) and No. 3 (L3).

\subsection{Reference Power for Microturbine Unit}

In this section, it is assumed that the reference active power of microturbine unit has been reduced by $25 \%$ of rated power, and subsequently increased to its rated power. Fig. 13a shows the instantaneous active power of external $\mathrm{AC}$ grids and MT unit as well as AC and DC loads. It can be said that the suggested control strategy for MT converter provides reasonable response. As shown in Fig. 13a, the instantaneous active power of network converters $\left(P_{n 1}\right.$ and $\left.P_{n 2}\right)$ are equal showing the proper load sharing.

Fig. 13b also depicts the DC bus voltage, which experiences a swell while the reference of the active power has been decreased and returns to the nominal DC voltage, $\left(V_{d c, r e f}\right)$. It is also clear that when the reference of the active power has been increased to the rated power, the DC bus voltage experiences sag phenomena. As it can be seen the actual DC bus voltage $\left(V_{d c}\right)$ follows the DC voltage $\left(V_{d c, d y}\right)$ and matches the results determined by equation (3). The other simulation results, which are not presented in this paper, can be verified by equations (16), (21) and (28).

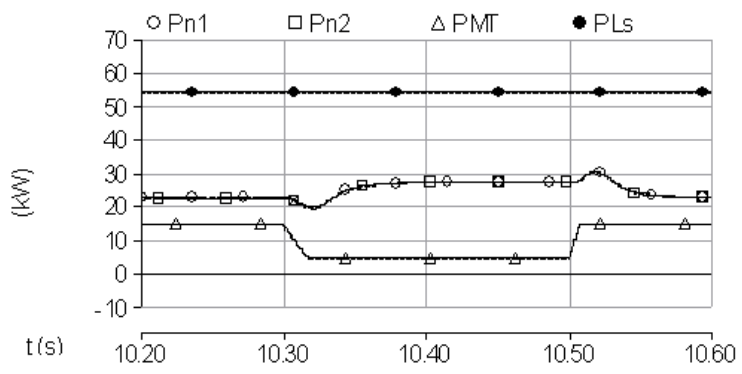

Fig. 13a. Active power variations.

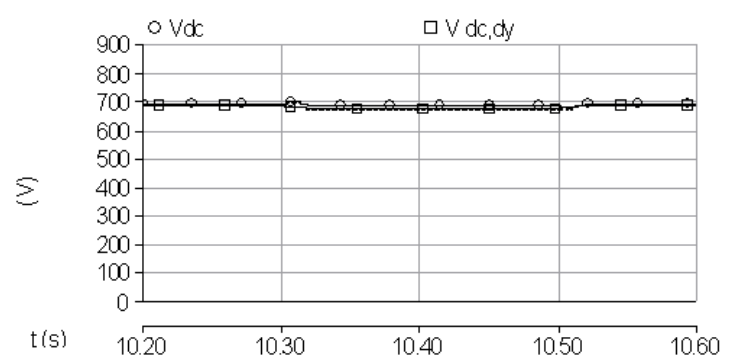

Fig. 13b. DC bus voltage.
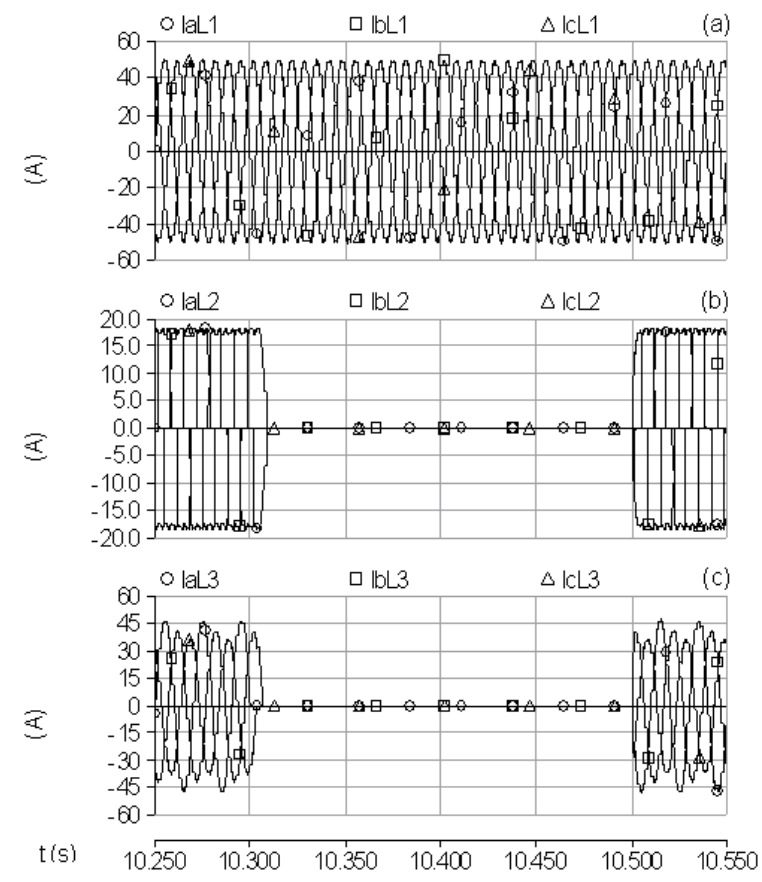

Fig. 14. Nonlinear load phase current.

\subsection{Temporary Loss of Load Converter}

Fig. 14 to 16 shows the simulation results due to the loss of the load converters No 2 and No. 3. Fig. 14 shows the phase currents of AC loads due to the loss of the associated converters for 0.2 second (from $\mathrm{t}=10.3 \mathrm{~s}$ till $\mathrm{t}=10.5 \mathrm{~s}$ ). 
Fig. 15a shows the instantaneous active power of external AC grids and MT unit as well as AC and DC loads. In this situation due to the loss of the load converters No. 2 and No. 3, the network converters return the additional power from the DC bus to the external AC system.

Fig. 15a also shows that the injected active power to the DC bus by MT unit is reduced. The proposed control strategy for MT converter is able to response during abnormal operating conditions. Fig. 15b shows the DC bus voltage,

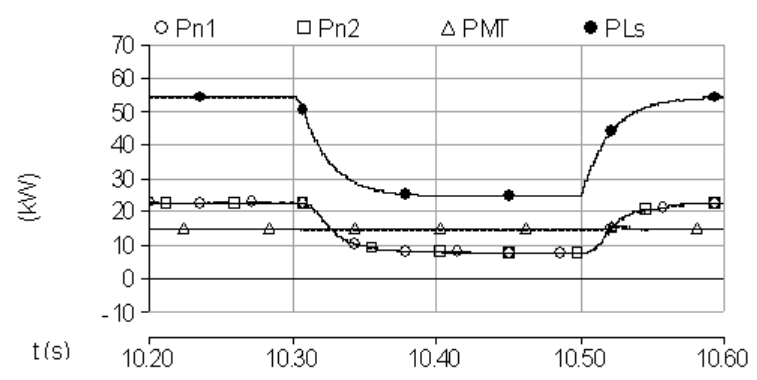

Fig. 15a. Active power variations.

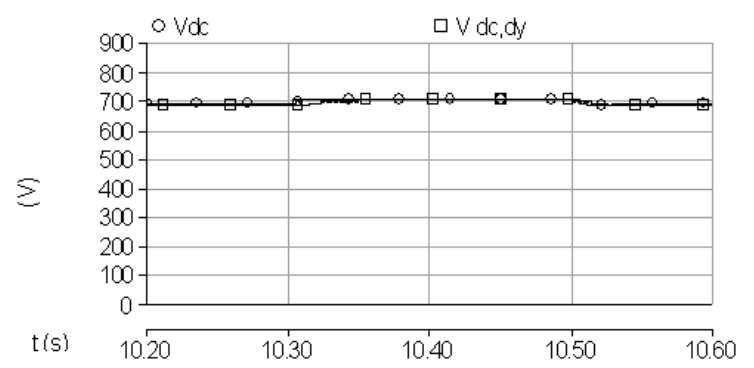

Fig. 15b. DC bus voltage.
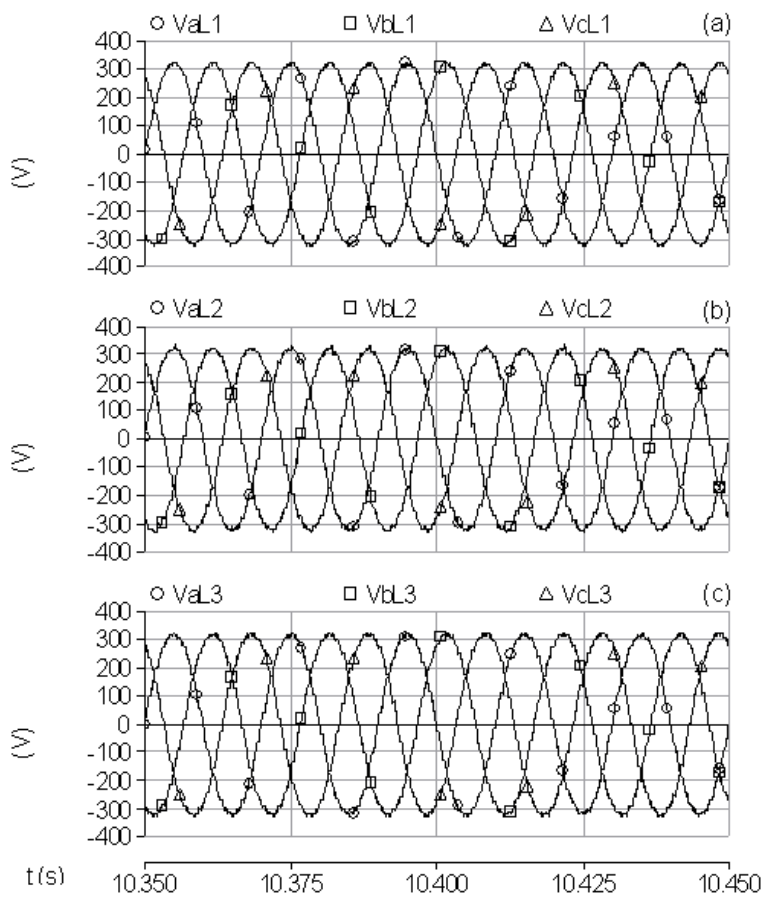

Fig. 16. Grid-side phase voltages of the load converters No. 1 (L1), No. 2 (L2) and No. 3 (L3). which is within acceptable limit. As it can be seen the actual DC bus voltage $\left(V_{d c}\right)$ follows the DC voltage $\left(V_{d c, d y}\right)$ and matches the results determined by equation (3). The other simulation results, which are not presented in this paper, can be verified by equations (16), (21) and (28).

Fig. 16 depicts the phase voltages at the terminal of the sensitive load ( $V_{a L 1}, V_{b L 1}$ and $V_{c L 1}$ ), the nonlinear load $\left(V_{a L 2}, V_{b L 2}\right.$ and $\left.V_{c L 2}\right)$ and the unbalanced load ( $V_{a L 2}$, $V_{b L 2}$ and $\left.V_{c L 2}\right)$, respectively. It is clear that these voltages are not affected by the loss of the converters. To quantify the level of the voltage unbalance, the percentage of unbalance is expressed in accordance with the definition of the "degree of unbalance in three phase system" [24]. In this case, the negative sequence unbalance is lower then $1 \%$ which is acceptable. It must be noticed that international standards admit unbalances lower than $2 \%$ [24].

\section{Conclusion}

In this paper it is shown that the DC distribution system accompanied with microturbine unit provide premium power quality services. Unlike previous works on the premium power park, the role of the microturbine unit and the power electronic converters in the proposed system are examined in regards to mitigating the impacts of the fault disturbances on loads. Analysis of the power system response and the design of the control system of the DC distribution system have been also presented. The proposed system is able to compensate the voltage sags, swells and voltage interruption under different operating conditions. In this paper PSCAD/EMTDC software has been used for the modeling and the simulation of the system component and proposed control strategies for power electronic interfaces, in order to investigate the DC bus voltage behaviors, power quality problems and load sharing. The results show that the proposed strategies provide the suitable load sharing between network converters, while the DC bus voltage remains with acceptable level. The results also show that the proposed system can protect the sensitive load against disturbances. It is shown that the nonlinear load does not inject harmonic currents to the $\mathrm{AC}$ grid and unbalancing would not be occurred in the AC grid by the nonlinear load. The efficacy of the scheme is born out by simulation results.

\section{References}

[1] Johnson, B. K. and R. Lasseter, 1993. An Industrial Power Distribution System Featuring UPS Properties. In Proceedings of the 24th Annual IEEE Power Electronics Specialists Conference, 20-24 June 1993.

[2] Ghosh A. and Joshi A., 2004. The Concept and Operating Principles of a Mini Custom Power Park. IEEE Transactions on Power Delivery, 19 (4): 1766-1774. 
[3] Choi S. S., Li B. H., and Vilathgamuwa D. M., 2002. Design and Analysis of the Inverter-side Filter used in the Dynamic Voltage Restorer. IEEE Transactions on Power Delivery, 17 (3): 857-864.

[4] Ghosh A. and Ledwich G., 2002. Compensation of Distribution System Voltage using DVR. IEEE Transactions on Power Delivery, 17 (4): 1030-1036.

[5] Iyer S., Ghosh A., Joshi A., 2005. Inverter Topologies for DSTATCOM Applications-a Simulation Study. Electric Power Systems Research, 75 (2): 161-170.

[6] Ghosh A. and Ledwich G., 2003. Load Compensating DSTATCOM in Weak AC Systems. IEEE Transactions on Power Delivery, 18 (4): 1302-1309.

[7] Fujita H. and Akagi H., 1998. The Unified Power Quality Conditioner: The Integration of Series- and Shunt-active Filters. IEEE Transactions on Power Electronics. 13 (2): 315-322.

[8] Ghosh A. and Ledwich G., 2001. A Unified Power Quality Conditioner (UPQC) for Simultaneous Voltage and Current Compensation. Electric Power Systems Research, 59 (1): 55-63.

[9] Ise T., 2002. Functions and Configurations of Quality Control Center on FRIENDS. Transmission and Distribution Conference and Exhibition, 6-10 October 2002, Asia Pacific.

[10] Domijan A., Montenegro A., Keri A. J. F. and Mattern K. E., 2005. Simulation Study of the World's First Distributed Premium Power Quality Park. IEEE Transactions on Power Delivery, 20 (2): 1483-1492.

[11] Weixing Lu and Boon-Teck Ooi, 2005. Premium Quality Power Park Based on Multi-Terminal HVDC. IEEE Transactions on Power Delivery, 20 (2): 978-983.

[12] Ghosh A., 2005. Performance Study of Two Different Compensating Devices in a Custom Power Park. IEE Proceeding Generation, Transmission and Distribution, July 2005, 152 (4): 521-528.

[13] Thand G.S., Zhang R., Xing K., Lee F.C. and Boroyevich D., 1999. Modeling, Control and Stability Analysis of a PEBB based DC DPS. IEEE Transactions on Power Delivery, 14 (2): 497-505.

[14] Gruzs T., Hall J., 2000. AC, DC or Hybrid Power Solutions for Today's Telecommunications Facilities. In Proceedings of the 22th International Telecommunications Energy Conference, 10-14 September 2000, Phoenix, AZ.

[15] Baran M. E., and Mahajan N. R., 2003. DC Distribution for Industrial Systems: Opportunities and Challenges. IEEE Transactions on Industry Applications, 39 (6): 1596-1601.

[16] Paul D., 2002. DC Traction Power System Grounding. IEEE Transactions on Industry Applications, 38 (3): 818-824.

[17] Marei M. I., El-Saadany E. F. and Salama M. M. A., 2004. A Novel Control Algorithm for the DG Interface to Mitigate Power Quality Problems. IEEE Transactions on Power Delivery, 19 (3): 1384-1392.

[18] Agustoni A., Brenna M. and Tironi E., 2003. Proposal for a High Quality DC Network with Distributed
Generation. In Proceedings of the 17th International Conference on Electricity Distribution, Barcelona, 1215 May 2003.

[19] Mahmoodi M., Gharehpetian G. B., Abedi M., Noroozian R., 2006. Novel and Simple Control Strategy for Fuel Cell Converters in DC Distribution Systems, In Proceedings of the First International Power and Energy Conference PECon 2006, 28-29 November 2006, Putrajaya, Malaysia.

[20] Mahmoodi M., Gharehpetian G. B., Abedi M., Noroozian R., 2006. A Suitable Control Strategy for Source Converters and a Novel Load- Generation Voltage Control Scheme for DC Voltage Determination in DC Distribution Systems. In Proceedings of the First International Power and Energy Conference PECon 2006, 28-29 November 2006, Putrajaya, Malaysia.

[21] Karlsson P. and Svensson J., 2003. DC Bus Voltage Control for a Distributed Power System. IEEE Transactions on Power Electronics, 18 (6): 1405-1412.

[22] Guda S., Wang C., and Nehrir M., 2006. Modeling of Microturbine Power Generation Systems. Electric Power Components and Systems, 34 (9): 1027-1041.

[23] Al-Hinai A., Feliachi A., 2002. Dynamic Model of a Microturbine Used as a Distributed Generator. IEEE Proc. 34-th Southeastern Symposium on System Theory, 18-19 March 2002.

[24] Short, T. (2004). Electric Power Distribution Handbook. CRC Press.

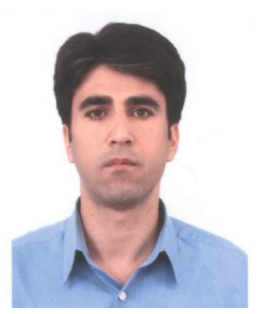

Reza Noroozian was born in Bonab, Iran, in 1975. He received the B.Sc. degree from the Tabriz University, Tabriz, Iran, in 2000, and M.Sc. and Ph.D. degrees from the Amirkabir University of Technology (AUT), Tehran, Iran, in 2003 and 2008, respectively, all Electrical Engineering. Currently, he is an Assistant professor in the Department of Electrical Engineering, Faculty of Engineering, Zanjan University, Zanjan, Iran. His research interests include Power System, Distributed Generation, Power Electronic and Power Quality.

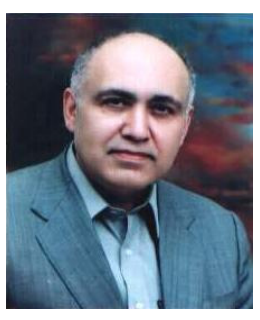

Mehrdad Abedi received his B.Sc., M. Sc. and Ph.D. from Tehran University, London University and Newcastle University in 1970, 1973, and 1977, respectively. He worked for G.E.C. (U.K) till 1978. Since then he joined EE Dept of Amirkabir University (Tehran, Iran) where he is now the professor and member of Center of Excellency on Power System. Prof. Abedi has published more than 25 books and 160 papers in journals and conferences. He is distinguished professor in Iran and is prize winner for two outstanding books. He is also member of Iranian Academy of Science and member of CIGRE. His main interest is electrical machines and power systems modeling, operation and control. 


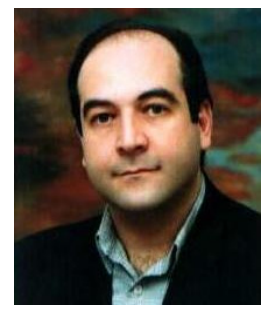

Gevorg B. Gharehpetian was born in Tehran, in 1962. He received his BS and MS degrees in electrical engineering in 1987 and 1989 from Tabriz University, Tabriz, Iran and Amirkabir University of Technology (AUT), Tehran, Iran, respectively, graduating with First Class Honors. In 1989 he joined the Electrical Engineering Department of AUT as a lecturer. $\mathrm{He}$ received the Ph.D. degree in electrical engineering from Tehran University, Tehran, Iran, in 1996. As a Ph.D. student he has received scholarship from DAAD (German Academic Exchange Service) from 1993 to 1996 and he was with High Voltage Institute of RWTH Aachen, Aachen, Germany. He held the position of Assistant Professor in AUT from 1997 to 2003, and has been Associate Professor since 2004. Dr. Gharehpetian is a Senior Member of Iranian Association of Electrical and Electronics Engineers (IAEEE), member of IEEE and member of central board of IAEEE. Since 2004 he is the Editor-in-Chief of the Journal of IAEEE. The power engineering group of AUT has been selected as a Center of Excellency on Power Systems in Iran since 2001. He is a member of this center and since 2004 the Research Deputy of this center. Since November 2005 he is the director of the industrial relation office of AUT. He is the author of more than 222 journal and conference papers. His teaching and research interest include power system and transformers transients, FACTS devices and HVDC transmission. 